\title{
Review Article \\ Polycystic Ovary Syndrome May Be an Autoimmune Disorder
}

\author{
Hifsa Mobeen, Nadeem Afzal, and Muhammad Kashif \\ Department of Immunology, University of Health Sciences, Lahore 54600, Pakistan \\ Correspondence should be addressed to Nadeem Afzal; immunology@uhs.edu.pk \\ Received 2 December 2015; Revised 10 March 2016; Accepted 11 April 2016 \\ Academic Editor: Malgorzata Wasniewska
}

Copyright (C) 2016 Hifsa Mobeen et al. This is an open access article distributed under the Creative Commons Attribution License, which permits unrestricted use, distribution, and reproduction in any medium, provided the original work is properly cited.

\begin{abstract}
Polycystic ovarian syndrome (PCOS) is the most prevalent endocrine disorder affecting females. It is a common cause of menstrual irregularities and infertility during reproductive age. Genetic and hormonal factors play crucial role in the pathogenesis of PCOS. Low level of progesterone in PCOS causes overstimulation of immune system that produces more estrogen which leads to various autoantibodies. Different autoantibodies have been documented in PCOS, for example, anti-nuclear (ANA), anti-thyroid, antispermatic, anti-SM, anti-histone, anti-carbonic anhydrase, anti-ovarian, and anti-islet cell antibodies. There is an association between PCOS and autoimmune diseases such as ANA and anti-TPO that have been documented in systemic lupus erythematosus and Hashimoto thyroiditis, respectively, and it is suspected that there are autoantibodies that might affect the long term clinical management of these patients. Therefore fluctuating levels of autoantibodies in different PCOS patients give us the way to open new chapter for future research on molecular level. This may lead to discovery of better treatment options for PCOS in near future.
\end{abstract}

\section{Polycystic Ovarian Syndrome}

In women polycystic ovarian syndrome (PCOS) was first described in 1935, by Stein and Leventhal $[1,2]$. PCOS is the most common cause of menstrual disturbance such as oligomenorrhea, anovulation, menorrhagia, and infertility [3].

PCOS was estimated to be $4-8 \%$ in Greece, Spain, and the USA. Throughout the world its prevalence is increasing and is showing galloping increase in parallel with type 2 diabetes mellitus (T2DM) [4]. Worldwide there were 116 million women affected by PCOS [5]. In Pakistan about 5\%$10 \%$ of women were affected by PCOS in 2009 [6]. Different signs and symptoms of PCOS along with their frequencies are shown in Table 1.

Regarding pathophysiology, PCOS is a heterogeneous disorder characterized by ovulatory dysfunction, hyperandrogenism, and polycystic ovarian morphology. Its characteristic neuroendocrine features include increased serum concentration of luteinizing hormone (LH), increased LH/FSH ratio, and increase in amplitude and frequency of pulsatile LH secretion (Figure 1) [7-9].

Hypothalamus secretes gonadotrophin releasing hormone $(\mathrm{GnRH})$ which binds its receptors on secretory cells of adenohypophysis [10, 11]. In response to GnRH, gonadotrophs produce $\mathrm{LH}$ and $\mathrm{FSH}$, which regulate development, growth, pubertal maturation, and reproductive processes of body [12].

In females FSH and $\mathrm{LH}$ activate ovaries to produce estrogen and inhibin, to regulate menstrual cycle. Estrogen forms a negative feedback loop by inhibiting production of GnRH by hypothalamus [12].

PCOS can affect not only females but also males but with less frequency. Although men do not have ovaries but underlying defects (high levels of androgens and low level steroid binding globulin) and clinical features of PCOS can also be seen in males and they are referred to as SteinLeventhal syndrome (Figure 1) [13-15].

The level of progesterone is decreased in PCOS which cannot suppress GnRH/LH pulse frequency in PCOS; therefore, increased estrogen secretion may lead to autoantibodies, for example, anti-nuclear, anti-thyroid, and anti-islet cell antibodies [16].

Currently there are two widely accepted diagnostic criteria of PCOS and both suggest presence of two out of three signs to be labeled as PCOS (Table 2) [17-19].

Obesity exacerbates comorbidities of PCOS such as hypertension, diabetes, hypercholesterolemia, and heart disease $[20,21]$. An ovulation in PCOS leads to unopposed estrogen secretion which is a risk factor for endometrial 


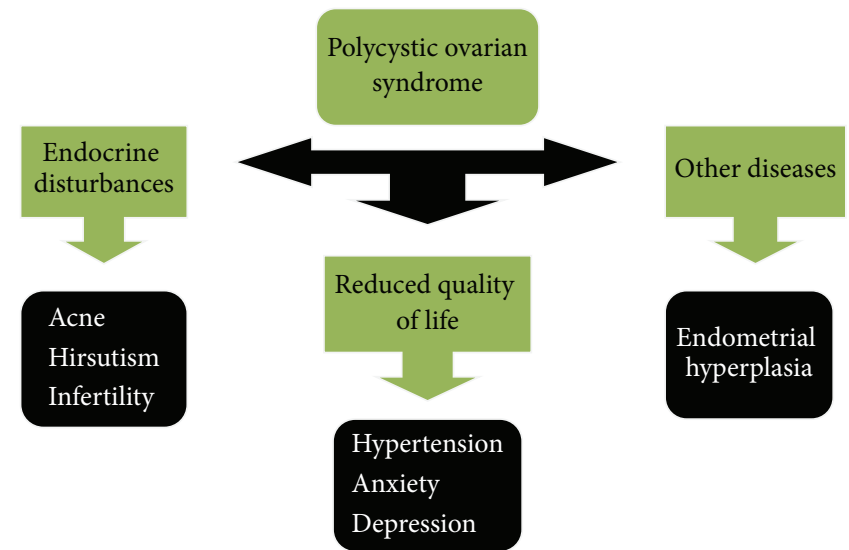

FIGURE 1: Flow chart showing possible consequences and outcomes of PCOS.

TABLE 1: Frequency of different clinical features of PCOS.

\begin{tabular}{lc}
\hline Clinical signs and symptoms of PCOS & Frequencies \\
\hline Oligomenorrhea & $80-90 \%[28,29]$ \\
\hline Amenorrhea & $30-40 \%[29]$ \\
& $10-75 \%[30]$ \\
\hline Hypergonadism & $70 \%[31]$ \\
\hline Polycystic ovaries & $90 \%[32]$ \\
\hline Hirsutism & $50 \%[33]$ \\
\hline Acne & $70 \%[31]$ \\
\hline Alopecia & $15 \%-30 \%[34]$ \\
\hline Infertility & $<10 \%[35,36]$ \\
\hline Overweight $/$ obese & $40 \%[37]$ \\
\hline${ }^{*}$ The majority of PCOS patients were overweight $\left(\mathrm{BMI}=25\right.$ and $\left.<30 \mathrm{~kg} / \mathrm{m}^{2}\right)$ \\
to obese $\left(\right.$ BMI $\left.=30 \mathrm{~kg} / \mathrm{m}^{2}\right)$, although one-third were of normal weight or \\
even underweight.
\end{tabular}

hyperplasia and carcinoma. PCOS reduces quality of life by depression, anxiety, obesity, infertility, and hirsutism [22]. Kerchner et al. detected depression in $40 \%$ of women of PCOS and the incidence of suicide is increased up to 7-fold in PCOS (Figure 1) [23, 24].

\section{Autoimmunity: Could It Be a Causative Factor for PCOS?}

In autoimmunity there is breakdown of mechanisms responsible for self-tolerance and there is induction of an immune response against self-components. Autoimmunity is characterized by induction of autoreactive cells (e.g., B cells, T cells) and proteins (e.g., antibodies). Autoimmunity is classified as organ specific and nonorgan specific autoimmunity [25].

Examples of organ specific autoimmunity include Grave's disease, Hashimoto's thyroiditis, and IDDM [26] whereas examples of systemic autoimmunity are SLE, rheumatoid arthritis, rheumatic fever, and so forth [27].
TABLE 2: Clinical phenotypes represented by consensus guidelines for PCOS.

\begin{tabular}{ll}
\hline Criteria for PCOS & Consensus diagnostic points \\
\hline $\begin{array}{ll}\text { (1) Androgen Excess Society } & \text { (1) Hyperandrogenism } \\
\text { (AES) 2006 reaffirmed 1990 NIH } & \text { (2) Oligoanovulation and } \\
\text { criteria } & \text { polycystic ovaries } \\
\text { (2) Amsterdam ESHRE/ASRM } & \text { (3) Exclusion of other androgen } \\
\text { consensus (2010) reaffirmed } & \text { excess disorders [18] } \\
\text { Rotterdam 2003 criteria } & \end{array}$
\end{tabular}

\section{Etiology of Autoimmune Diseases}

Although exact reason for autoimmunity is not known, various mechanisms have been suggested for its development as follows.

3.1. Sequestered Antigens. Lymphoid cells may not be exposed to some of the self-antigens during their differentiation. The release of antigen from these organs due to accidental trauma, injury, or surgery can result in the stimulation of an immune response and initiation of autoimmune diseases, for example, sperms and neuron cells [39].

3.2. Molecular Mimicry. When environmental substances that resemble our body components are exposed to the body, the immune system generates response against these substances which cross-react with body's own tissue; for example, coxsackievirus has molecular mimicry with $\beta$ cells of pancreas [40].

3.3. Alteration of Normal Protein. Drugs can bind to normal proteins and make them immunogenic; for example, methyldopa binds to RBC's surface proteins and causes autoimmune haemolytic anaemia [41].

3.4. Failure or Decrease of T Regulatory Cells (Tregs). Tregs are characterized by the expression of CD4, CD25, and FOXP3. They suppress proinflammatory effects of other $\mathrm{T}$ cells by producing IL-10 and play role in peripheral tolerance of 
autoreactive $\mathrm{T}$ cells. If there is failure or decrease of Tregs, then autoreactive cells will not be killed and ultimately may lead to autoimmunity [42].

In PCOS there is an excess of estrogen which has been linked to different autoimmune diseases. Estrogen increases production of IL-4, IL-1, IL-6, and interferon- $\gamma$.

\section{Autoantibodies in PCOS}

4.1. Anti-Nuclear Antibody (ANA). Inflammation, immune hyperstimulation, and process of tissue destruction expose intracellular antigens that lead to production of ANA which is a hallmark of autoimmune disorders [43]. ANA has been detected in many autoimmune disorders such as systemic lupus erythematosus, Sjogren's syndrome, polymyositis, dermatomyositis, and autoimmune hepatitis [43-46].

4.2. Anti-Thyroid Antibody. Autoantibodies against one or more components of thyroid are produced in autoimmune thyroiditis. Anti-thyroid antibodies include anti-thyroid peroxidase (anti-TPO), thyrotrophic receptor (TRAbs), and thyroglobulin antibodies [47]. Anti-TPO antibodies are associated with Hashimoto thyroiditis [48-51]. CD4 T cells produce INF- $\gamma$ which induces MHC-II on thyroid cells that expands autoreactive $\mathrm{T}$ cells and prolongs inflammatory response [51].

Patrikova et al. has suggested strong association of anti-thyroid antibodies with PCOS, for example, anti-TPO $7.81 \%$ [52]. Kachuei et al. reported strong association of anti-thyroglobulin $(p=0.275)$ and anti-TPO antibodies $(p=0.040)$ in PCOS patients [53]. Arduc et al. suggested association of anti-thyroglobulin $(p=0.039)$ and antiTPO antibodies $(p=0.002)$ in PCOS [54]. Janssen et al. suggested that autoimmune thyroiditis (AIT) is three times more common in PCOS as compared to non-PCOS women of reproductive age [55]. Sarkar reported strong association of infertility, miscarriages, and disturbed thyroid profile in pregnant females. Both hypo- and hyperthyroidism can lead to increased rate of miscarriages, fetal death, and late cognitive development of offsprings [56].

4.3. Anti-Islet Cell Antibody. Islet cell autoantibodies are produced when beta cells of pancreas are damaged and they can bind to glutamic acid decarboxylase (GAD), protein tyrosine phosphatase, islet antigen-2 (IA-2), insulin, and zinc transporter (ZNT8) and lead to further destruction of islet cells of pancreas [63]. The destruction of beta cells of pancreas causes hyperglycemia, which can be treated by insulin therapy to control hyperglycemia, but it leads to increase in weight gain as well as ovarian hyperandrogenism [64].

Islet cell autoantibodies react with islet cell antigens in particular sequence reacting with insulin or GAD first, followed by IA-2 and ZNT8. This sequence of autoimmunity to different islet cell proteins indicates that destruction of insulin producing cells is progressing in a particular sequence. These autoantibodies can be used to estimate an individual's risk of developing type I diabetes [64]. Gardener et al. reported anti-islet cell antibodies in $83 \%$ of PCOS patients [63].
TABLE 3: Reported autoantibodies in PCOS.

\begin{tabular}{lc}
\hline Autoantibodies & $\begin{array}{c}\text { Documented findings of different } \\
\text { studies }\end{array}$ \\
\hline ANA & $8.6 \%[43]$ \\
$p<0.001[46]$
\end{tabular}

In PCOS low level of progesterone overstimulates immune system that leads to production of autoantibodies and therefore it can be labeled as an autoimmune disorder [61]. Summary of the autoantibodies that have been detected so far in PCOS is given in Table 3.

Females with PCOS are at increased risk for endometrial cancer, whereas their risks for breast and ovarian cancer are similar to those of women in the general population [65]. Nulliparity, obesity, and prolonged unopposed increase in estrogen are some of the health consequences of PCOS that are associated with cancer [66-69]. A study carried out by Barry found a significant threefold increase in risk for endometrial cancer among women with PCOS but no significant excess risks for either breast or ovarian cancer [70].

Females of PCOS present with complaints of infertility, which is often anovulatory in nature. These patients are often treated by conventional ovulation-induction medications, such as clomiphene citrate (CC) or gonadotropins, as firstline therapy. These agents increase risks for multiple pregnancies and in case of gonadotropins, there is an increased risk for ovarian hyperstimulation syndrome. Both of these drug modalities increase the risk for ovarian cyst formation, pain, and/or ovarian torsion. Metformin has been used extensively to treat infertility and pregnancy issues [71]. 


\section{Insulin Resistance, Obesity, and Androgens as Potential Source of Autoimmunity in PCOS}

PCOS is essentially a hormonal disorder and is buttressed by insulin resistance and hyperandrogenism $[72,73]$. Recently Mezaal et al. have reported involvement of insulin directly or indirectly in the production of sex hormones. They reported many insertions, deletion, and substitutions of INS gene in PCOS patients by gene sequencing; they suggested that insulin resistance can affect sexual function adversely and may even cause PCOS [74]. The pathophysiologic linkage between PCOS and type 1DM has been declared as autoimmune phenomenon but it is still not established. Researchers have suggested that exogenous insulin given as the treatment of type 1DM may contribute to the development of PCOS in these patients [75]. Nonphysiologically administered exogenous insulin can potentially stimulate the production of androgens by ovaries [76]. Codner et al. postulated that aggressive insulin therapy may be accounted for the development of PCOS in females of type 1DM. They reported high frequency of hyperandrogenism and PCOS in patients of type 1DM, which appears to be associated with aggressive exogenous insulin therapy [77].

Obesity which is common in PCOS patients further increases the risk of insulin resistance which in turn causes hyperandrogenism and risk of developing PCOS [78, 79]. However, the relationship between hyperandrogenism and metabolic features of PCOS is still very controversial. So far differing findings have been reported for the pathogenic role of different types of androgens in patients of PCOS [80]. Considering literature, for the better understanding of pathophysiologic mechanisms of PCOS, emphasis should be given to the role of autoimmunity in PCOS and its relationship with obesity, insulin resistance, and hyperandrogenism. This will help to further enhance the knowledge of clinicians about suitable diagnostic, preventive, and curative interventions for women with PCOS.

\section{Avenues for the Future Research and Conclusion}

There is an association between PCOS and autoimmune diseases such as ANA and anti-TPO that have been documented in systemic lupus erythematosus and Hashimoto thyroiditis, respectively, and it is suspected that there are autoantibodies that might affect the long term clinical management of these patients. Therefore fluctuating levels of autoantibodies in different PCOS patients give us the way to open new chapter for future research on molecular level. This may lead to discovery of better treatment options for PCOS in near future.

Since thyroid autoimmune markers are present in patients of PCOS, therefore, PCOS patients should be investigated for autoimmune markers of thyroid. Further, disturbances of estrogen, progesterone, and thyroid profile are causative factors of gynaecological problems that eventually may lead to fetal loss and occurrence of endometrial, ovarian, and breast cancers.
Further studies are needed at genetic and molecular level to establish the contribution of autoimmunity in PCOS. It is hoped that, with the advancements of diagnostic facilities, researchers would be able to establish early markers for the diagnosis and monitoring of PCOS and its associated disorders and maybe for its better prognosis.

\section{Competing Interests}

The authors declare that they have no competing interests.

\section{Acknowledgments}

The authors are thankful to the administration of University of Health Sciences Lahore, Pakistan, for providing access to scholarly research articles.

\section{References}

[1] I. F. Stein and M. L. Leventhal, "Amenorrhea associated with bilateral polycystic ovaries," American Journal of Obstetrics and Gynecology, vol. 29, no. 2, pp. 181-191, 1935.

[2] M. Asunción, R. M. Calvo, J. L. San Millá N, H. F. EscobarMorreale, J. Sancho, and S. Avila, "A prospective study of the prevalence of the polycystic ovary syndrome in unselected Caucasian women from Spain," Journal of Clinical Endocrinology and Metabolism, vol. 85, no. 7, pp. 2434-2438, 2000.

[3] P. G. Ovesen, N. Moller, and S. Greisen, "Polycystic ovarysyndrome clinical presentation and treatment," Ugeskrift for Laeger, vol. 160, no. 3, pp. 260-264, 1998.

[4] M. A. Ganie and S. Kalra, "Polycystic ovary syndromea metabolic malady, the mother of all lifestyle disorders in women-can Indian health budget tackle it in future?" Indian Journal of Endocrinology and Metabolism, vol. 15, no. 4, pp. 239241, 2011.

[5] G. R. Mohan, "A case of poly cystic ovarian syndrome treated with Homoeopathy," 2010, http://homoeocuredrmohan.blogspot.com/2013/10/a-case-of-poly-cystic-ovarian-syndrome.html.

[6] R. Azziz, E. Carmina, and D. Dewailly, "The Androgen Excess and PCOS Society criteria for the polycystic ovary syndrome: the complete task force," Fertility and Sterility, vol. 91, pp. 456488, 2009.

[7] S. S. Yen, P. Vela, and J. Rankin, "Inappropriate secretion of follicle-stimulating hormone and luteinizing hormone in polycystic ovarian disease," The Journal of Clinical Endocrinology \& Metabolism, vol. 30, no. 4, pp. 435-442, 1970.

[8] R. Rebar, H. L. Judd, S. S. C. Yen, J. Rakoff, G. Vandenberg, and F. Naftolin, "Characterization of the inappropriate gonadotropin secretion in polycystic ovary syndrome," The Journal of Clinical Investigation, vol. 57, no. 5, pp. 1320-1329, 1976.

[9] J. Waldstreicher, N. F. Santoro, J. E. Hall, M. Filicori, and W. F. Crowley Jr., "Hyperfunction of the hypothalamic-pituitary axis in women with polycystic ovarian disease: indirect evidence for partial gonadotroph desensitization," Journal of Clinical Endocrinology and Metabolism, vol. 66, no. 1, pp. 165-172, 1988.

[10] R. P. Millar, A. J. Pawson, C. A. Flanagan, K. Morgan, and S. R. Maudsley, "Gonadotropin-releasing hormone receptor," Endocrine Reviews, vol. 25, no. 2, pp. 235-275, 2004.

[11] H. Charlton, "Hypothalamic control of anterior pituitary function: a history," Journal of Neuroendocrinology, vol. 20, no. 6, pp. 641-646, 2008. 
[12] S. V. Meethal, T. Liu, H. W. Chan et al., "Identification of a regulatory loop for the synthesis of neurosteroids: a steroidogenic acute regulatory protein-dependent mechanism involving hypothalamic-pituitary-gonadal axis receptors," Journal of Neurochemistry, vol. 110, no. 3, pp. 1014-1027, 2009.

[13] O. Lunde, P. Magnus, L. Sandvik, and S. Hoglo, "Familial clustering in the polycystic ovarian syndrome," Gynecologic and Obstetric Investigation, vol. 28, no. 1, pp. 23-30, 1989.

[14] R. Kurzrock and P. R. Cohen, "Polycystic ovary syndrome in men: Stein-Leventhal syndrome revisited," Medical Hypotheses, vol. 68 , no. 3, pp. 480-483, 2007.

[15] J. Zavadilova, J. Vrbikova, M. Vankova et al., "Role of D327N sex-hormone binding globulin gene polymorphism in the pathogenesis of polycystic ovary syndrome," Endocrine Abstracts, vol. 11, article 709, 2006.

[16] M. W. A. Angstwurm, R. Gärtner, and H. W. L. ZieglerHeitbrock, "Cyclic plasma IL-6 levels during normal menstrual cycle," Cytokine, vol. 9, no. 5, pp. 370-374, 1997.

[17] K. E. Sharquie, A. A. Al-Bayatti, A. I. Al-Ajeel, A. J. AlBahar, and A. A. Al-Nuaimy, "Free testosterone, luteinizing hormone/follicle stimulating hormone ratio and pelvic sonography in relation to skin manifestations in patients with polycystic ovary syndrome," Saudi Medical Journal, vol. 28, no. 7, pp. 10391043, 2007.

[18] R. Azziz, E. Carmina, D. Dewailly et al., "Positions statement: criteria for defining polycystic ovary syndrome as a predominantly hyperandrogenic syndrome: an Androgen Excess Society guideline," The Journal of Clinical Endocrinology and Metabolism, vol. 91, no. 11, pp. 4237-4245, 2006.

[19] J. Adams, S. Franks, D. W. Polson et al., "Multifollicular ovaries: clinical and endocrine features and response to pulsatile gonadotropin releasing hormone," The Lancet, vol. 2, no. 84698470, pp. 1375-1379, 1985.

[20] R. D. Sinclair and R. P. R. Dawber, "Androgenetic alopecia in men and women," Clinics in Dermatology, vol. 19, no. 2, pp. 167178, 2001.

[21] A. M. Venkatesan, A. Dunaif, and A. Corbould, "Insulin resistance in polycystic ovarian syndrome: progress and paradoxes recent progress in hormone research," Journal of Biomedicine and Biotechnology, vol. 56, pp. 295-308, 2001.

[22] S. M. Grundy, H. B. Brewer Jr., J. I. Cleeman, S. C. Smith Jr., and C. Lenfant, "Definition of metabolic syndrome: report of the National Heart, Lung, and Blood Institute/American Heart Association conference on scientific issues related to definition," Circulation, vol. 109, pp. 433-438, 2004.

[23] A. Kerchner, W. Lester, S. P. Stuart, and A. Dokras, "Risk of depression and other mental health disorders in women with polycystic ovary syndrome: a longitudinal study," Fertility and Sterility, vol. 91, no. 1, pp. 207-212, 2009.

[24] M. Månsson, J. Holte, K. Landin-Wilhelmsen, E. Dahlgren, A. Johansson, and M. Landén, "Women with polycystic ovary syndrome are often depressed or anxious-a case control study," Psychoneuroendocrinology, vol. 33, no. 8, pp. 1132-1138, 2008.

[25] W. Levinson, "Mycobacteria," in Review of Medical Microbiology and Immunology, pp. 150-154, McGraw-Hill, New York, NY, USA, 2010.

[26] A. Huber, F. Menconi, S. Corathers, E. M. Jacobson, and Y. Tomer, "Joint genetic susceptibility to type 1 diabetes and autoimmune thyroiditis: from epidemiology to mechanisms," Endocrine Reviews, vol. 29, no. 6, pp. 697-725, 2008.
[27] L. C. Kottyan, E. E. Zoller, J. Bene et al., “The IRF5-TNPO3 association with systemic lupuserythematosus has two components that other autoimmunedisorders variably share," Human Molecular Genetics, vol. 24, no. 2, pp. 582-596, 2015.

[28] C. Farquhar, "Introduction and history of polycystic ovary syndrome," in Polycystic Ovary Syndrome, pp. 4-24, Cambridge University Press, Cambridge, UK, 2nd edition, 2007.

[29] R. Hart, "Definitions, prevalence and symptoms of polycystic ovaries and the polycystic ovary syndrome," in Polycystic Ovary Syndrome, pp. 15-26, Anshan, Kent, UK, 2007.

[30] T. L. Marx and A. E. Mehta, "Polycystic ovary syndrome: pathogenesis and treatment over the short and long term," Cleveland Clinic Journal of Medicine, vol. 70, no. 1, pp. 31-45, 2003.

[31] B. C. J. M. Fauser, B. C. Tarlatzis, R. W. Rebar et al., "Consensus on women's health aspects of polycystic ovary syndrome (PCOS): the Amsterdam ESHRE/ASRM-Sponsored 3rd PCOS Consensus Workshop Group," Fertility and Sterility, vol. 97, no. 1, pp. 28-38.e25, 2012.

[32] J. Adams, D. W. Polson, and S. Franks, "Prevalence of polycystic ovaries in women with anovulation and idiopathic hirsutism," British Medical Journal, vol. 293, no. 6543, pp. 355-359, 1986.

[33] I. Souter, L. A. Sanchez, M. Perez, A. A. Bartolucci, and R. Azziz, "The prevalence of androgen excess among patients with minimal unwanted hair growth," American Journal of Obstetrics and Gynecology, vol. 191, no. 6, pp. 1914-1920, 2004.

[34] C. N. Wijeyaratne, A. H. Balen, J. H. Barth, and P. E. Belchetz, "Clinical manifestations and insulin resistance (IR) in polycystic ovary syndrome (PCOS) among south Asians and Caucasians: is there a difference?" Clinical Endocrinology, vol. 57, no. 3, pp. 343-350, 2002.

[35] E. Guastella, R. A. Longo, and E. Carmina, "Clinical and endocrine characteristics of the main polycystic ovary syndrome phenotypes," Fertility and Sterility, vol. 94, no. 6, pp. 2197-2201, 2010.

[36] Rotterdam ESHRE/ASRM-Sponsored PCOS Consensus Workshop Group, "Revised 2003 consensus on diagnostic criteria and long-term health risks related to polycystic ovary syndrome (PCOS)," Human Reproduction, vol. 19, pp. 41-47, 2004.

[37] H. Teede, A. Deeks, and L. Moran, "Polycystic ovary syndrome: a complex condition with psychological, reproductive and metabolic manifestations that impacts on health across the lifespan," BMC Medicine, vol. 8, article 41, 2010.

[38] J. Vrbikova and V. Hainer, "Obesity and polycystic ovary syndrome," Obesity Facts, vol. 2, no. 1, pp. 26-35, 2009.

[39] H. Lassmann and R. M. Ransohoff, "The CD4-Th1 model for multiple sclerosis: a critical [correction of crucial] re-appraisal," Trends in Immunology, vol. 25, no. 3, pp. 132-137, 2004.

[40] L. Andréoletti, D. Hober, C. Hober-Vandenberghe et al., "Detection of Coxsackie B virus RNA sequences in whole blood samples from adult patients at the onset of type I diabetes mellitus," Journal of Medical Virology, vol. 52, no. 2, pp. 121-127, 1997.

[41] M. A. M. Van Boekel and W. J. Van Venrooij, "Modifications of arginines and their role in autoimmunity," Autoimmunity Reviews, vol. 2, no. 2, pp. 57-62, 2003.

[42] E. M. Shevach, "Regulatory T cells in autoimmmunity," Annual Review of Immunology, vol. 18, no. 1, pp. 423-449, 2000.

[43] A. Samsami Dehaghani, N. Karimaghaei, M. E. Parsanezhad, M. Malekzadeh, M. Mehrazmay, and N. Erfani, "Anti-nuclear antibodies in patients with polycystic ovary syndrome before 
and after laparoscopic electrocauterization," Iranian Journal of Medical Sciences, vol. 38, no. 2, pp. 187-190, 2013.

[44] R. Cervera, J. Font, M. Ramos-Casals et al., "Primary Sjogren's syndrome in men: clinical and immunological characteristics," Lupus, vol. 9, no. 1, pp. 61-64, 2000.

[45] P. Obermayer-Straub, C. P. Strassburg, and M. P. Manns, "Autoimmune hepatitis," Journal of Hepatology, Supplement, vol. 32, no. 1, pp. 181-197, 2000.

[46] A. K. Makled, H. M. Fathi, M. F. Gomaa, and R. M. Bakr, "Serologic markers of autoimmunity in women with polycystic ovary syndrome," Middle East Fertility Society Journal, vol. 20, no. 2, pp. 86-90, 2015.

[47] D. S. Cooper, "Subclinical hypothyroidism," The New England Journal of Medicine, vol. 345, no. 4, pp. 260-265, 2001.

[48] P. Saravanan and C. M. Dayan, "Thyroid autoantibodies," Endocrinology and Metabolism Clinics of North America, vol. 30, no. 2, pp. 315-337, 2001.

[49] J. Orgiazzi, "Anti-TSH receptor antibodies in clinical practice," Endocrinology Metabolism Clinics of North America, vol. 29, no. 2, pp. 339-355, 2000.

[50] C. M. Boyd and J. R. Baker, "The immunology of thyroid cancer," Endocrinology Metabolism Clinics of North America, vol. 25, no. 1, pp. 159-179, 1996.

[51] R. D. Utiger, Werner and Ingbar's the Thyroid: A Fundamental and Clinical Text, Lippincott Williams \& Wilkins, Philadelphia, Pa, USA, 9th edition, 2005.

[52] J. Petrikova, I. Lazurova, I. Dravecka et al., "The prevalence of non organ specific and thyroid autoimmunity in patients with polycystic ovary syndrome," Biomedical Papers of the Medical Faculty of the University Palacky, Olomouc, Czechoslovakia, vol. 159, no. 2, pp. 302-306, 2015.

[53] M. Kachuei, F. Jafari, A. Kachuei, and A. H. Keshteli, "Prevalence of autoimmune thyroiditis in patients with polycystic ovary syndrome," Archives of Gynecology and Obstetrics, vol. 285, no. 3, pp. 853-856, 2012.

[54] A. Arduc, B. A. Dogan, S. Bilmez et al., "High prevalence of Hashimoto's thyroiditis in patients with polycystic ovary syndrome: does the imbalance between estradiol and progesterone play a role?" Endocrine Research, vol. 40, no. 4, pp. 204-210, 2015.

[55] O. E. Janssen, N. Mehlmauer, S. Hahn, A. H. Öffner, and R. Gärtner, "High prevalence of autoimmune thyroiditis in patients with polycystic ovary syndrome," European Journal of Endocrinology, vol. 150, no. 3, pp. 363-369, 2004.

[56] D. Sarkar, "Recurrent pregnancy loss in patients with thyroid dysfunction," Indian Journal of Endocrinology and Metabolism, vol. 16, no. 2, pp. 350-351, 2012.

[57] A. Menteşe, S. Guven, A. Sumer et al., "Serum anti-carbonic anhydrase I and II antibodies and polycystic ovary syndrome," Turkish Journal of Biochemistry, vol. 38, no. 1, pp. 43-48, 2013.

[58] K. R. George and N. A. Malini, "Infertility in females in context of antispermantibodies in pelvic inflammatory disease (PID) andpolycystic ovarian syndrome (PCOS)," The Bioscan, vol. 7, no. 1, pp. 47-51, 2012.

[59] J. Petríková and I. Lazúrová, "Ovarian failure and polycystic ovary syndrome," Autoimmunity Reviews, vol. 11, no. 6-7, pp. A471-A478, 2012.

[60] S. G. Gardner, E. A. Gale, A. J. Williams et al., "Progression to diabetes in relatives with islet autoantibodies. Is it inevitable?" Diabetes Care, vol. 22, no. 12, pp. 2049-2054, 1999.
[61] D. A. Samsami, P. Razmjoei, and M. E. Parsanezhad, "Serum levels of anti-histone and anti-double-strand DNA antibodies before and after laparoscopic ovarian drilling in women with polycystic ovarian syndrome," Journal of Obstetrics and Gynecology of India, vol. 64, no. 1, pp. 47-52, 2014.

[62] B. Hamedi, E. K. Sarvestani, A. Khalili et al., "Evaluation of ANA-related serologic autoantibodies in polycystic ovary syndrome," Immunology, Endocrine and Metabolic Agents in Medicinal Chemistry, vol. 14, no. 1, pp. 21-25, 2014.

[63] S. G. Gardener, E. A. M. Gale, A. J. K. Williams et al., "Progression to diabetes in relatives with islet autoantibodies. Is it inevitable?" Diabetes Care, vol. 22, no. 12, pp. 2049-2054, 1999.

[64] H. E. Lebovitz, "Adjunct therapy for type 1 diabetes mellitus," Nature Reviews Endocrinology, vol. 6, no. 6, pp. 326-334, 2010.

[65] M. Gottschau, S. K. Kjaer, A. Jensen, C. Munk, and L. Mellemkjaer, "Risk of cancer among women with polycystic ovary syndrome: a Danish Cohort study," Gynecologic Oncology, vol. 136, no. 1, pp. 99-103, 2015.

[66] A. G. Renehan, M. Tyson, M. Egger, R. F. Heller, and M. Zwahlen, "Body-mass index and incidence of cancer: a systematic review and meta-analysis of prospective observational studies," The Lancet, vol. 371, no. 9612, pp. 569-578, 2008.

[67] World Cancer Research Fund/American Institute for Cancer Research, Continuous Update Project Report. Food, Nutrition, Physical Activity, and the Prevention of Breast Cancer, American Institute for Cancer Research, Washington, Wash, USA, 2010.

[68] World Cancer Research Fund/American Institute for Cancer Research, Continuous Update Project Report. Food, Nutrition, Physical Activity, and the Prevention of Ovarian Cancer, WCRF, Washington, DC, USA, 2014.

[69] F. Amant, P. Moerman, P. Neven, D. Timmerman, E. Van Limbergen, and I. Vergote, "Endometrial cancer," The Lancet, vol. 366, no. 9484, pp. 491-505, 2005.

[70] J. A. Barry, M. M. Azizia, and P. J. Hardiman, "Risk of endometrial, ovarian and breast cancer in women with polycystic ovary syndrome: a systematic review and meta-analysis," Human Reproduction Update, vol. 20, no. 5, Article ID dmu012, pp. 748758, 2014.

[71] R. S. Legro, M31-PCOS: Use of Metformin to Allow Pregnancy: Other Treatments, Department of Obstetrics \& Gynecology, Penn State College of Medicine, M.S. Hershey Medical Center, Hershey, Pa, USA, 2013.

[72] H. J. Teede, M. L. Misso, A. A. Deeks et al., "Assessment and management of polycystic ovary syndrome: summary of an evidence-based guideline," Medical Journal of Australia, vol. 195, no. 6, pp. S65-S112, 2011.

[73] N. K. Stepto, S. Cassar, A. E. Joham et al., "Women with polycystic ovary syndrome have intrinsic insulin resistance on euglycaemic-hyperinsulaemic clamp," Human Reproduction, vol. 28, no. 3, pp. 777-784, 2013.

[74] M. I. Mezaal, M. I. Nader, and I. H. Aziz, "Molecular study of insulin resistance and polycystic ovary syndrome," American Journal of Medicine and Medical Sciences, vol. 5, no. 3, pp. 121125, 2015.

[75] H. F. Escobar-Morreale, B. Roldán, R. Barrio et al., "High prevalence of the polycystic ovary syndrome and hirsutism in women with type 1 diabetes mellitus," Journal of Clinical Endocrinology and Metabolism, vol. 85, no. 11, pp. 4182-4187, 2000.

[76] J. F. Cara and R. L. Rosenfield, "Insulin-like growth factor I and insulin potentiate luteinizing hormone-induced androgen 
synthesis by rat ovarian thecal-interstitial cells," Endocrinology, vol. 123, no. 2, pp. 733-739, 1988.

[77] E. Codner, N. Soto, P. Lopez et al., "Diagnostic criteria for polycystic ovary syndrome and ovarian morphology in women with type 1 diabetes mellitus," The Journal of Clinical Endocrinology \& Metabolism, vol. 91, no. 6, pp. 2250-2256, 2006.

[78] B. O. Yildiz, G. Bozdag, Z. Yapici, I. Esinler, and H. Yarali, "Prevalence, phenotype and cardiometabolic risk of polycystic ovary syndrome under different diagnostic criteria," Human Reproduction, vol. 27, no. 10, pp. 3067-3073, 2012.

[79] D. S. Kiddy, P. S. Sharp, D. M. White et al., "Differences in clinical and endocrine features between obese and non-obese subjects with polycystic ovary syndrome: an analysis of 263 consecutive cases," Clinical Endocrinology, vol. 32, no. 2, pp. 213220, 1990.

[80] M. W. O’Reilly, A. E. Taylor, N. J. Crabtree et al., "Hyperandrogenemia predicts metabolic phenotype in polycystic ovary syndrome: the utility of serum androstenedione," Journal of Clinical Endocrinology \& Metabolism, vol. 99, no. 3, pp. 10271036, 2014. 


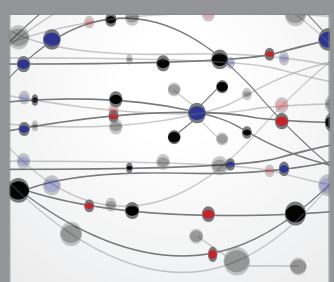

The Scientific World Journal
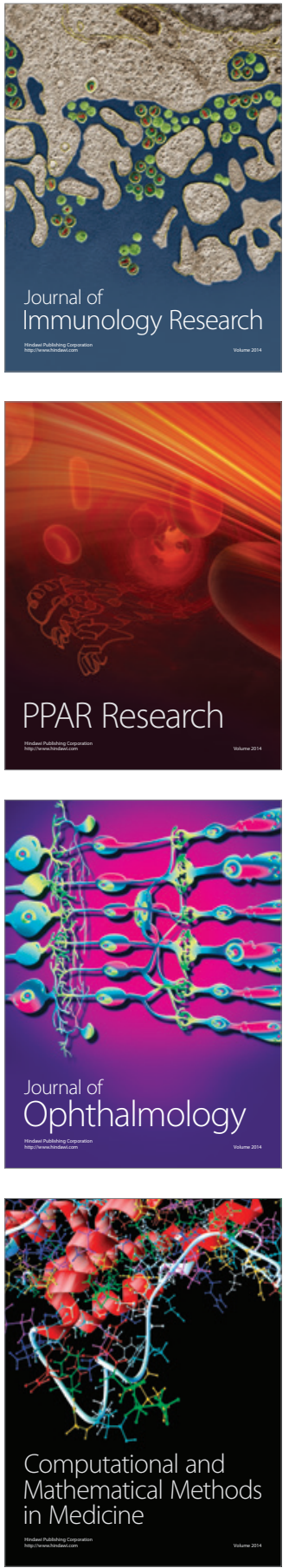

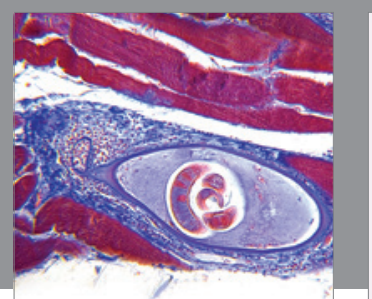

Gastroenterology Research and Practice

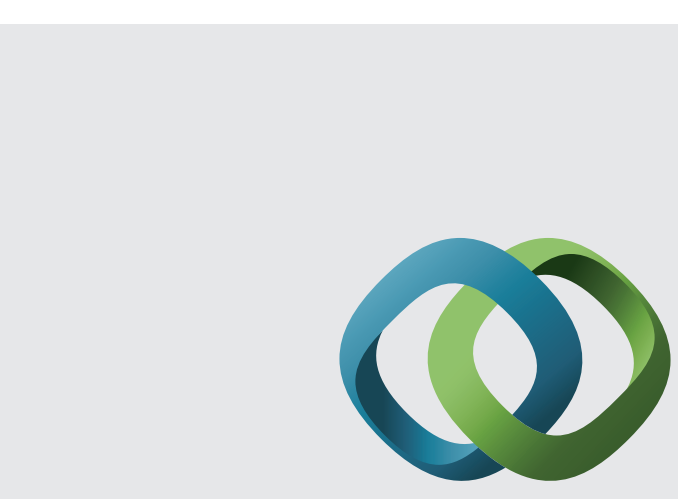

\section{Hindawi}

Submit your manuscripts at

http://www.hindawi.com
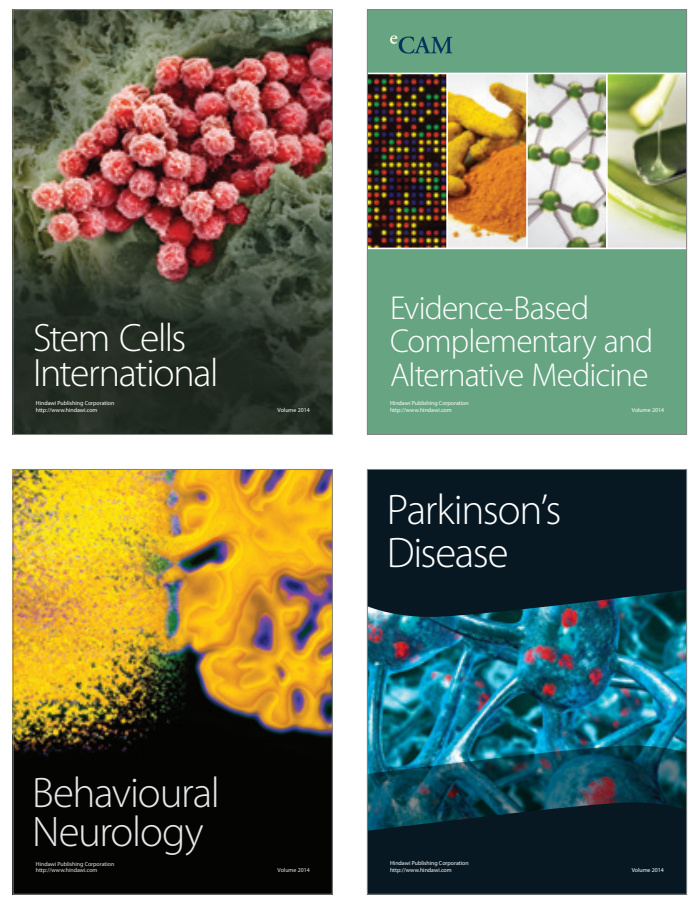
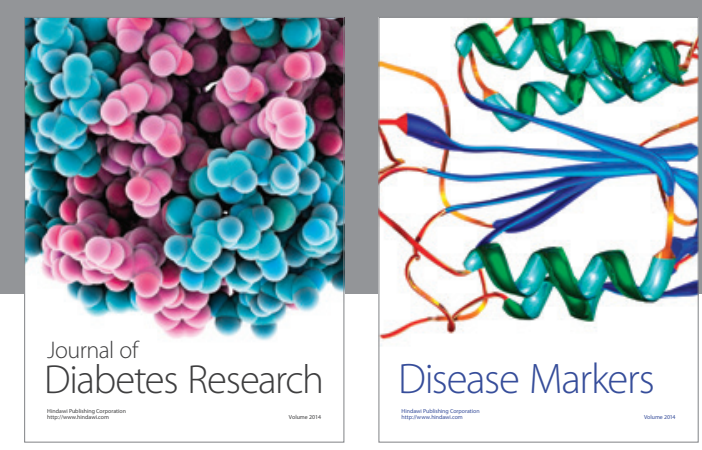

Disease Markers
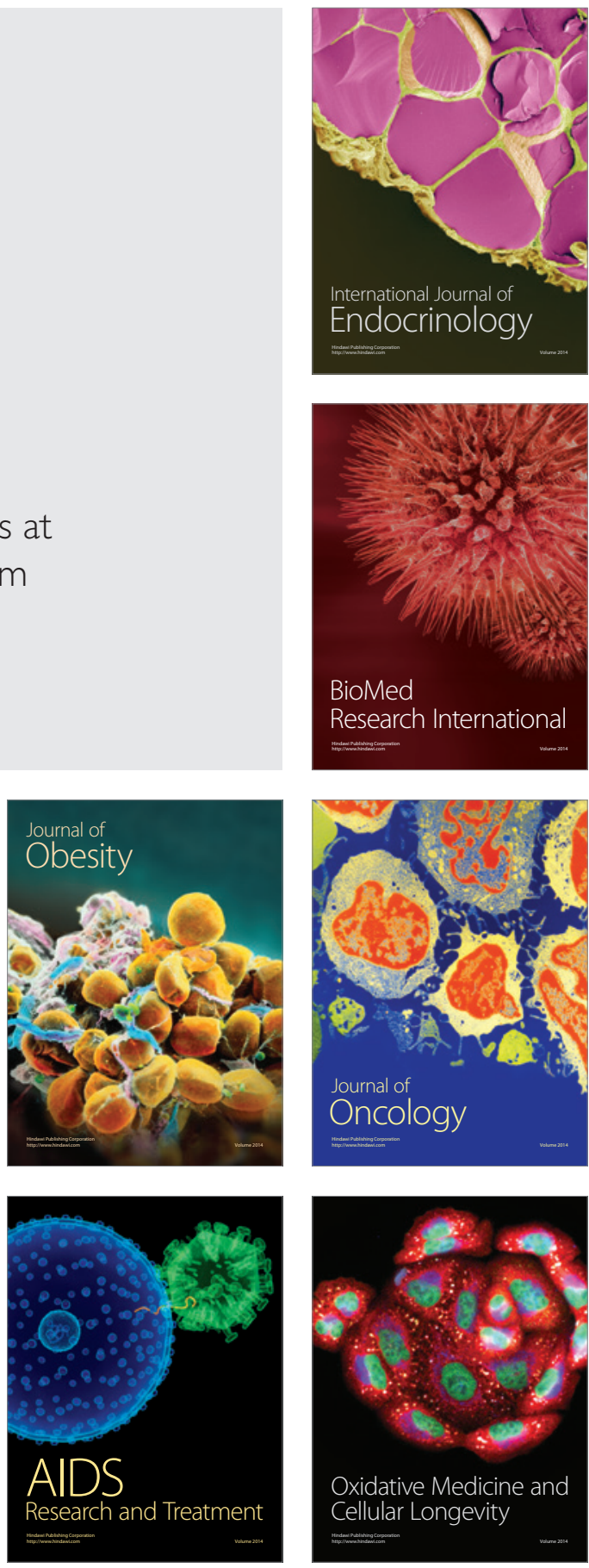